\title{
Fitts' Law for Angular Foot Movement in the Foot Tapping Task
}

\author{
Jaeeun Park, Rohae Myung \\ Department of Industrial Management Engineering, Korea University, Seoul, 136-713
}

\begin{abstract}
Objective: The purpose of this study was to confirm difference between angular foot movement time and existing foot Fitts' law predicting times, and to develop the angular foot Fitts' law in the foot tapping task. Background: Existing studies of foot Fitts' law focused on horizontal movement to predict the movement time. However, when driving a car, humans move their foot from the accelerator to the brake with a fixed heel. Therefore, we examined the experiment to measure angular foot movement time in reciprocal foot tapping task and compared to conventional foot Fitts' law predicting time. And, we developed the angular foot Fitts' law. Method: In this study, we compared the angular foot movement time in foot tapping task and the predicted time of four conventional linear foot Fitts' law models - Drury's foot Fitts' law, Drury's ballistic, Hoffmann's ballistic, Hoffmann's visually-controlled. 11 subjects participated in this experiment to get a movement time and three target degrees of 20,40, and 60 were used. And, conventional models were calculated for the prediction time. To analyze the movement time, linear and arc distance between targets were used for variables of model. Finally, the angular foot Fitts' law was developed from experimental data. Results: The average movement times for each experiment were $412.2 \mathrm{~ms}, 474.9 \mathrm{~ms}$, and $526.6 \mathrm{~ms}$ for the $89 \mathrm{~mm}, 172 \mathrm{~mm}$, and $253 \mathrm{~mm}$ linear distance conditions. The results also showed significant differences in performance time between different angle level. However, all of conventional linear foot Fitts' laws ranged $135.6 \mathrm{~ms}$ to $401.2 \mathrm{~ms}$. On the other hand, the angular foot Fitts' law predicted the angular movement time well. Conclusion: Conventional linear foot Fitts' laws were underestimated and have a limitation to predict the foot movement time in the real task related angular foot movement. Application: This study is useful when considering the human behavior of angular foot movement such as driving or foot input device.
\end{abstract}

Keywords: Fitts' law, Angular movement, Foot movement time, Human-computer-interaction, User behavior

\section{Introduction}

최근 인간과 상호작용하는 여러 시스템의 기능이 다양하 게 발전하면서 손 만으로 조작하기 부족한 경우 발은 보조 적인 입력수단으로 매우 유용하게 사용되고 있다. 대표적인 예로 운전 중 페달 조작은 차량의 속도를 조작하는 데 핵심
적인 요소로서 운전대를 조작하는 것과 함께 필수적인 행 동이다. 이는 간단하지만 매우 중요하다. 만약 운전자의 발 운동을 묘사할 때 0.5 초만 잘못 예측하더라도 시속 $100 \mathrm{~km}$ 로 달리는 차량의 경우 $14 \mathrm{~m}$ 를 더 진행할 수 있다. 이러한 중요성 때문에 최적의 페달 간격과 크기를 찾기 위해 페달 조작 시간, 운전자의 편의성 등을 고려하는 것이 매우 중 요하다(Davies and Watts, 1969; Glaser and Halcomb,

Corresponding Author: Rohae Myung. Department of Industrial Management Engineering, Korea University, Seoul, $136-713$.

Mobile: +82-10-8915-3392, E-mail: rmyung@korea.ac.kr

Copyright@2012 by Ergonomics Society of Korea(pISSN:1229-1684 eISSN:2093-8462). All right reserved.

(c) This is an open-access article distributed under the terms of the Creative Commons Attribution Non-Commercial License(http://creativecommons.org/licenses/by-nc/3.0/), which permits unrestricted non-commercial use, distribution, and reproduction in any medium, provided the original work is properly cited. http://www.esk.or.kr 
1980). 또한 운전자의 불편함을 고려한 엑셀레이터와 브레 이크의 최적위치 등을 결정하기 위해 시뮬레이션이나 목업 (Mockup)을 이용한 연구들이 많았다(Kim and Seo, 2005; Kim and Jung, 2007). 이와 함께 특정한 작업영역 또는 몸 이 불편한 사람들을 위한 사용자 인터페이스로 발의 움직임 과 발로 조작하는 방식에 대해 다양한 연구가 이루어져 왔다 (Kroemer, 1971; Morrison et al., 1986; Kim and Kaber, 2009).

한편, 인간과 시스템의 인터페이스를 연구하는 과정에서 매우 중요한 요소 중 하나로 운동 시간을 정량적으로 예측하 고 표현할 수 있는 모델인 Fitts' law가 제시되었다. 이는 인 간의 지각, 인지, 운동 과정을 이해하는 기초가 되고, 인간 정신-운동 행동에 관한 모델로 정보처리이론에 바탕을 두고 있다(Byrne and Anderson, 1998; Mackenzie, 1989). 그 러나 Fitts' law에 관한 이전의 연구는 주로 손에 의한 운동 에 초점을 두고 있어, 발 운동에 관한 행태와 운동 시간을 예측하는 데 한계가 있었다. 이에 따라 개별적인 발 운동의 수행 시간을 예측하기 위하여 foot Fitts' law에 대한 연구가 진행되었다. 기존 연구에서는 Fitts' law의 가장 기본적인 운 동 행태를 근거로 하여 Figure $1 \mathrm{a}$ 와 같이 페달 간의 수평적 인 형태의 움직임에 초점을 두었다. 여러 연구에서는 이를 적용하여 발로 조작하는 인터페이스의 수행 시간을 예측하 고 사용자의 행동양식을 묘사하였다(Welford, 1960; Fitts, 1964; Drury, 1975; Hoffmann, 1991a; Hoffmann, 1991b;

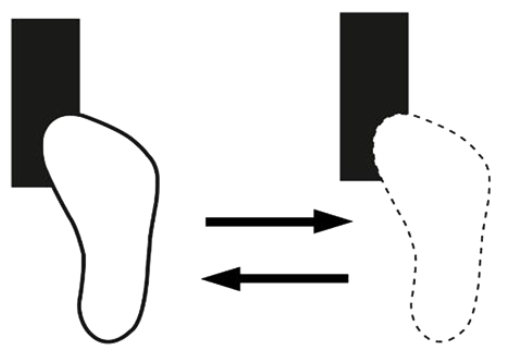

(a)

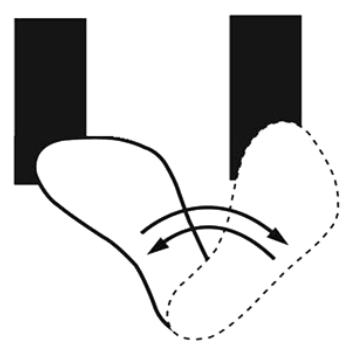

(b)

Figure 1. (a) Linear foot movement (b) Angular foot movement
Mackenzie, 1992; Campos and Calado, 2009).

그러나 운전 중 페달을 조작하는 발 운동은 수평적인 움직 임 뿐 아니라 발뒤꿈치가 고정되어 호를 그리는 형태가 나타 난다. 비디오 관찰법으로 실제 도로에서 주행 시 운전자의 발 동작을 관찰한 기존 연구에 의하면, 피실험자 15 명 중 $80 \%$ 인 12 명이 뒤꿈치가 고정된 채 브레이크와 엑셀레이 터를 조작하는 V자 형태의 움직임을 보였다(Park et al., 2012). 또한 본 연구를 위해 자체적으로 실시한 설문조사에 서 1년 이상 운전 경험이 있는 20 30대 성인남녀 59명 중 $64 \%$ 이상인 38명이 발 뒤꿈치를 고정한 상태에서 브레이 크와 엑셀레이터를 조작한다고 응답했다.

즉 앞선 연구와 설문조사를 종합해보면, 실제 운전 시 페 달을 조작하는 발 움직임은 Figure $1 \mathrm{~b}$ 와 같이 페달 간의 호 를 그리는 angular movement 형태가 나타남을 알 수 있다. 또한 지금까지 Fitts' law의 연구에서 손 운동은 다양한 인터 페이스와 움직임에 맞춰 여러 연구가 있었으나, 발 운동에 대해서는 여러 형태의 연구가 진행되지 않았다.

따라서 본 연구에서는 호를 그리는 형태의 발 운동 시간에 대하여 기존의 foot Fitts' law가 예측하는 운동 시간과 비교 하여 차이를 확인하고 이를 잘 나타낼 수 있는 angular foot Fitts' law를 제시하고자 한다.

\section{Foot Fitts' Law}

Fitts' law는 인간의 정신적 움직임을 설명하고 예측하기 위한 모델로 여러 분야에서 다양한 연구가 진행되었다. Fitts (1954)에 의하면 인간은 정보를 처리하는 하나의 시스템 으로 간주되고, 특정 작업 시 인간의 수행 시간을 정량적으 로 측정이 가능함을 밝혔다. 따라서 Fitts' law는 인간의 지 각, 인지, 운동 행태를 이해하는 기초가 된다(Miller 1953). 이러한 점에 기반하여 인간의 움직임에 대한 운동 시간 (Movement time)을 다음과 같이 Fitts' law equation으로 나타낼 수 있다.

$$
\mathrm{MT}=\mathrm{a}+\mathrm{b} \log _{2}(2 \mathrm{D} / \mathrm{W})
$$

위 Equation 1에서 $\log _{2}(2 \mathrm{D} / \mathrm{W})$ 는 난이도(Index of difficulty)를 나타내는 것으로 $\mathrm{D}$ 는 distance를 의미하며 시 작 지점의 중심부터 목표 타겟의 중심까지 거리를 나타낸다. 또한 $\mathrm{W}$ 는 width를 의미하며 타겟의 너비를 나타낸다. $\mathrm{a}$ 와 $\mathrm{b}$ 는 상수로 실험 결과에 따라 회귀식을 통해 결정된다. 따라 서 타겟 간의 거리(D)가 증가하거나 타겟의 너비(W)가 작 아지는 경우 난이도가 증가하게 되고, 이와 함께 운동 시간 
(MT: movement time)이 증가함을 나타낸다.

이러한 Fitts' law는 신체 중에서도 주로 손에 의한 인터 페이스를 묘사하는 연구가 활발히 진행되었는데, 발 동작의 운동 시간을 알아보기 위한 초기 연구는 Drury(1975)에 의 해 이루어졌다. Drury는 $25 \mathrm{~mm}$ 와 $50 \mathrm{~mm}$ 너비의 페달에 대 해 여섯 수준의 거리 $(150 \mathrm{~mm}, 225 \mathrm{~mm}, 300 \mathrm{~mm}, 375 \mathrm{~mm}$, $525 \mathrm{~mm}, 675 \mathrm{~mm}$ )를 두고 Fitts' law를 개발하기 위한 반 복적인 foot tapping 실험을 진행하였다. 이 실험을 통해 페달을 조작하는 인간의 발 운동 시간을 예측하는 모델인 Equation 2를 제시했다.

$$
\mathrm{MT}=0.189+0.055 \mathrm{ID} ; \mathrm{r}^{2}=0.92
$$

페달의 너비를 $25 \mathrm{~mm}$ 와 $50 \mathrm{~mm}$ 로 하고, 난이도(ID)는 Fitts' law의 $\log _{2}(2 \mathrm{D} / \mathrm{W})$ 를 그대로 적용하였다. 이러한 Drury의 모델은 결정계수가 매우 높고 발 운동에 대한 초 기 연구임과 동시에 상당히 좋은 모델로 평가받았다. 그러나 Drury는 페달의 너비에 따른 차이는 운동 시간에 거의 영향 을 미치지 않는다고 하였다. 실제로 Drury의 실험 데이터에 서 $25 \mathrm{~mm}$ 페달과 $50 \mathrm{~mm}$ 페달 간의 가장 큰 운동 시간 차 이는 $16 \mathrm{~ms}$ 로 거의 차이가 없었다. 또한 Drury의 실험 조 건은 난이도(ID)가 0.92에서 3.4였는데, 이에 대해 Gan과 Hoffmann(1988)은 인간의 시각적인 처리에 대해 언급되어 있지 않는 것이라고 하였다. 따라서 Drury의 데이터를 재해 석하여 다음의 Equation 3을 제시했다.

$$
\mathrm{MT}=107+11.2 \sqrt{A} ; \mathrm{r}^{2}=0.97
$$

이는 난이도(ID)를 나타낼 때 타겟의 너비(W)를 제외 하고 타겟 간의 거리(Amplitude)만을 적용한 ballistic movement를 나타낸 것으로, 시각적인 요소를 배제한 것이 다. 즉 허벅지부터 발까지 근육 운동에 대해 이미 프로그램 되어 있어 보지 않고도 조작이 가능하다는 것이다. 따라서 발 운동 시간은 타겟 간의 거리에 의해서만 영향을 받는다고 가정하였다.

Hoffmann (1991b)은 기존의 발 운동 시간에 대한 연구들 이 엑셀레이터와 브레이크 같은 페달에 국한되어 있어 상세 한 움직임에 대해서는 표현하지 못한다고 하였다. 특히 작은 타겟으로 인해 시각적인 노력이 포함되어야 함을 고려하였 다. 따라서 기존의 Fitts' law 연구에서와 같이 타겟의 크기 와 너비를 다양하게 하여 난이도(ID) 3 을 기준으로 3 보다 큰 경우 visually-controlled foot movement를 Equation 4 와 같이 개발하고, 3 보다 작은 경우 ballistic foot movement 를 Equation 5와 같이 제시하였다.

$$
\mathrm{MT}=-57.7+115.5 \mathrm{ID}-34.6 \log _{2} \mathrm{~W} ; \mathrm{r}^{2}=0.984
$$

Equation 4 에서 난이도(ID) 는 Fitts' law의 $\log _{2}(2 \mathrm{D} / \mathrm{W})$ 를 나타내고, $\mathrm{W}$ 는 타겟의 너비를 나타낸다. 이 연구에서 시 각적인 처리를 나타내는 모델을 개발하기 위해 타겟의 너비 가 $5 \mathrm{~mm}, 10 \mathrm{~mm}, 20 \mathrm{~mm}$ 일 때, 타겟 간의 거리를 조정하여 난이도(ID)를 $3,4,5,6$ 으로 맞추어 실험을 진행하였다.

$$
\mathrm{MT}=107.5+6.5 \sqrt{A} ; \mathrm{r}^{2}=0.960
$$

Equation 5는 난이도(ID) 가 3보다 작은 경우를 나타내고, 타겟의 너비가 매우 커서 시각적인 요소와 관련이 없음을 나 타내기 위해 타겟 간의 거리(Amplitude)만 적용하였다. 이 연구에서 타겟의 거리를 $50 \mathrm{~mm}, 119 \mathrm{~mm}, 216 \mathrm{~mm}, 344 \mathrm{~mm}$, $500 \mathrm{~mm}$ 일 때, 타겟의 너비를 조정하여 난이도(ID)를 2 로 맞추어 실험을 진행하였다.

이러한 기존 연구를 통해 발을 이용한 인터페이스의 수행 시간을 예측할 수 있다. 그러나 서두에서 밝힌 바와 같이 현 재까지의 foot Fitts' law에 관한 연구에서는 타겟 간의 수 평적인 움직임에 초점을 두고 있다. 그러나 앞선 Park et al. (2012)의 연구와 설문조사 결과, 기존 foot Fitts' law는 호 를 그리는 형태의 움직임이 나타나는 실제 자동차의 엑셀레 이터와 브레이크를 조작하는 것을 묘사하고 예측하는 데 한 계가 있다.

따라서 페달 조작 시 호를 그리는 형태의 발 동작에 대한 연구가 필요하다.

\section{Experiment}

연구의 목적은 호를 그리는 발 동작의 실제 운동 시간을 측정하여 기존의 foot Fitts' law와 비교하고, angular foot Fitts' law를 개발하는 것이다. 실험의 조건은 Figure 2 와 같다.

\subsection{Subjects}

실험에는 26 30세의 성인 11 명 (남 7명, 여 4명)이 참여 하였다. 이들은 모두 발목을 움직이는 실험을 진행하는 데 신체적인 문제가 없었고, 타겟을 보기 위한 시각적인 문제도 전혀 없었다. 또한 실험 조건을 동일하게 하기 위해 발 크 기가 260 290mm인 사람으로 한정하였다. 피실험자의 평 균 발 크기는 $277.5 \mathrm{~mm}(\mathrm{SD}=7.72)$ 였다. 


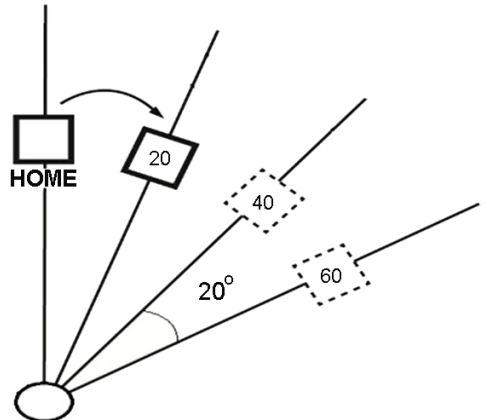

Figure 2. Experimental conditions

\subsection{Apparatus}

실험을 위한 발판에는 중심선을 기준으로 20도 간격의 참 조선이 20도, 40도, 60 도로 그어져 있다. 중심선의 가장 하 단부분에는 발꿈치를 고정하기 위한 홈이 파여있다. 중심선 상에는 'HOME' 타겟이 있고 참조선 상에는 목표 타겟이 각 각 1 개씩 총 3 개가 있다. 타겟과 홈의 거리는 타겟의 중심부 와 홈의 중심을 피실험자의 평균 발 크기인 $277.5 \mathrm{~mm}$ 가 되 도록 하였다. 또한 타겟의 너비를 $40 \mathrm{~mm} \times 40 \mathrm{~mm}$ 의 정사 각형으로 하여 모든 피실험자가 페달을 밟는 데 문제가 없도 록 하였다.

다음, 각 타겟의 중심을 포인트로 정하고 모든 타겟의 포인트 간의 거리를 나타내었다. 따라서 직선 거리는 20도 $-89 \mathrm{~mm}, 40$ 도 $-172 \mathrm{~mm}, 60$ 도 $-253 \mathrm{~mm}$ 이고 호의 길이 는 20 도 $-96.8 \mathrm{~mm}, 40$ 도 $-193.6 \mathrm{~mm}, 60$ 도 $-290 \mathrm{~mm}$ 이다. 'HOME' 타겟부터 각 목표 타겟의 거리를 적용한 난이도 (ID) 는 다음과 같다. 20 도- $2.2,40$ 도-3.1, 60도-3.7 이 는 실제 자동차에서 브레이크와 엑셀레이터 간의 거리가 약 $15 \mathrm{~cm}$ 로 한 것과 페달 조작이 가능한 관절 범위, 발 너비를 고려하여 결정되었다.

타겟은 컴퓨터에 연결되어 있어 이를 밟는 순간과 떼는 순 간에 전기적 신호로 변환되어 접촉 시간과 이탈 시간이 'ms' 단위로 측정되어 저장된다. 이를 계산하여 실제 운동 시간 인 'HOME' 타겟에서 발을 떼는 순간부터 각 목표 타겟에 발이 닿는 순간까지 운동 시간을 추출하게 된다. 따라서, 'HOME' 타겟에서 목표 타겟으로 이동한 것이 1 회가 된다.

\subsection{Task \& procedure}

실험을 시작하기 앞서 피실험자들은 자리에 앉아 발을 움 직이는 데 불편함이 없도록 의자의 높이와 위치를 조정하였 다. 의자를 조정한 후 피실험자들은 20도, 40도, 60도에 위 치해 있는 타겟을 밟는데 이상이 없는지 확인하고 불편한
경우 발판의 위치를 조정하였다. 이 후 실험을 위해 약 5 분 간 자유롭게 연습을 하였다. 또한 피실험자들에게 실험의 진 행이 어떻게 이루어지는지, 실험의 순서가 어떻게 되는지에 대한 정보를 주었다.

피실험자와 장비가 준비되면 피실험자는 발꿈치를 홈에 고정하고 발을 'HOME' 타겟으로부터 약 $2 \mathrm{~cm}$ 떨어뜨린 상 태에서 시작 신호를 기다린다. 실험 진행자의 지시에 의해 구두로 시작 신호를 받게 되면 피실험자는 해당 각도에 대해 서 'HOME' 타겟과 목표 타겟을 30회 연속으로 밟게 된다. 즉 ' $\mathrm{HOME}$ ' 타겟 $=>$ 목표 타겟 $=>$ 'HOME' 타겟 $\Rightarrow>$ 목표 타겟의 순서로 타겟을 밟으며 실험이 진행된다. 이는 기존의 Fitts' law와 비교하기 위해 Fitts' law를 도출하는 방식과 같게 진행된 것으로, 피실험자에게 가능한 정확하고 빠르게 타겟으로 발을 이동하도록 요구하였다. 실험 동안 피실험자 들은 가능한 편안하면서도 일정한 자세를 유지하였고 움직 임은 되도록 의자에서 대퇴부와 둔부는 가만히 있으되 무릎 아래 부분으로 움직이도록 하였다.

\subsection{Experimental design}

실험은 피실험자가 모든 수준에 대해 이루어지는 withinsubject design으로, 모든 피실험자는 각도에 따라 세 수준 에 대하여 각 30회씩 총 90회 실시하였다. 실험의 순서는 Table 1과 같이 라틴방격법으로 정하였다.

Table 1. Experimental sequence by Latin square

\begin{tabular}{c|c|c|c|c|c}
\hline \multirow{2}{*}{$\begin{array}{c}\text { Angle } \\
(\Theta)\end{array}$} & \multicolumn{5}{|c}{ Sequence of subjects } \\
\cline { 2 - 6 } & $\mathrm{S} 1$ & $\mathrm{~S} 2$ & $\mathrm{~S} 3$ & $\mathrm{~S} 4$ & $\mathrm{Sn}$ \\
\hline $20^{\circ}$ & 1 & 2 & 3 & 1 & $\cdots$ \\
\hline $40^{\circ}$ & 2 & 3 & 1 & 2 & $\cdots$ \\
\hline $60^{\circ}$ & 3 & 1 & 2 & 3 & $\cdots$ \\
\hline
\end{tabular}

이는 실험 순서가 동일하여 피로효과와 학습효과에 의해 실험 데이터가 오염되는 것을 방지하기 위함이다. 라틴방격 법에 의한 실험 순서는 $1,2, \mathrm{t}, 3, \mathrm{t}-1,4, \mathrm{t}-2$ 와 같은 순서 로 정해지며 여기서 $\mathrm{t}$ 는 총 task의 수이다. 다음 피실험자의 경우 앞서 정해진 순서에 1 씩 더하여 순서가 변하게 된다.

실험의 종속변수는 운동 시간 $(\mathrm{ms})$ 이고 독립변수는 기존 의 foot Fitts' law와 비교하기 위한 페달 간의 직선 거리 $(\mathrm{mm})$ 이다. 


\section{Results}

실험 데이터에서 피실험자의 실수로 인해 타겟을 두 번 누른 경우, 발 떨림에 의해 시간이 중복 측정된 경우, 그리 고 해당 수준의 목표 타겟이 아닌 다른 타겟을 누른 경우는 제외되었다. 실험 데이터는 피실험자당 90 회 $\times 11$ 명으로 총 990개이고, 이 중 37 개 데이터가 오류로 판정되었다.

각 수준에서 평균 운동 시간은 $89 \mathrm{~mm}$ (20도)에서 412.2 $\mathrm{ms}, 172 \mathrm{~mm}$ (40도)에서 $474.9 \mathrm{~ms}, 253 \mathrm{~mm}$ (60도)에서 $526.6 \mathrm{~ms}$ 로 나타났다. 또한 분산분석 결과 독립변수인 직선 거리 $[F(2,30)=11.440, p<0.001]$ 는 운동 시간에 서로 다 른 유의한 영향을 미치는 것으로 나타났다.

이러한 결과는 기존 연구(John, 2002)에서 실제 운전 시 측정한 엑셀레이터와 브레이크 간의 발 운동 시간(400 $500 \mathrm{~ms}$ ) 의 범위와 일치한다. 즉 실제로 페달을 조작하는 경 우 호를 그리는 형태의 발 운동이 나타남을 알 수 있다.

\subsection{Comparison with existing linear foot Fitts' law}

실험을 통해 얻은 경험적인 값과 타겟 간의 직선 거리를 기준으로 예측한 기존 Fitts' law 모델값을 먼저 비교한 다 음, 타겟 간의 호의 길이를 기준으로 예측한 기존 Fitts' law 모델값을 비교하였다. 이는 거리에 따라 운동 시간(MT)에 영향을 받는 모델 예측값의 특성을 반영하고 다방면으로 비 교하기 위함이다.

실험 결과와 비교하기 위해 사용된 모델은 Drury(1975) 와 Hoffmann(1991b)의 모델로 총 네 개의 foot Fitts' law이다. 이는 앞선 문헌 연구에 맞춰 선정되었다. 또한 본 실험의 난이도(ID)는 2.2 3.9이다. Hoffmann(1991b)의 연구에서 난이도(ID) 3 을 기준으로 ballistic과 visuallycontrolled movement를 구분하였으므로 ballistic 모델과 함께 visually-controlled 모델을 함께 비교하였다. 따라 서 Drury의 foot Fitts' law, Drury의 ballistic Fitts' law, Hoffmann의 ballistic Fitts' law, 그리고 Hoffmann의 visually-controlled Fitts' law를 사용하였다. 즉 네 가지의 모델을 통해 얻은 운동 시간의 예측 값과 실험을 통해 얻은 값을 비교하였다.

먼저, 타겟 간의 직선 거리를 각 모델에 적용해서 예측한 운동 시간을 비교하여 Figure 3과 같은 결과를 도출했다. 가 장 뚜렷이 나타나는 결과는 호를 그리는 발 동작을 나타내는 angular movement의 운동 시간이 다른 모델들 보다 높게 나타난다는 것이다. 적게는 약 $100 \mathrm{~ms}$ 에서 많게는 $300 \mathrm{~ms}$ 까지 차이가 난다. 각 실험 수준에 대해 $95 \%$ 신뢰구간을 구 해보면, 20 도 $-89 \mathrm{~mm}$ (385.96< $\mu$ <438.36), 40도-172mm
(442.73< $\mu<507.17), 60$ 도 $-253 \mathrm{~mm}(486.78<\mu<566.33)$ 이다.

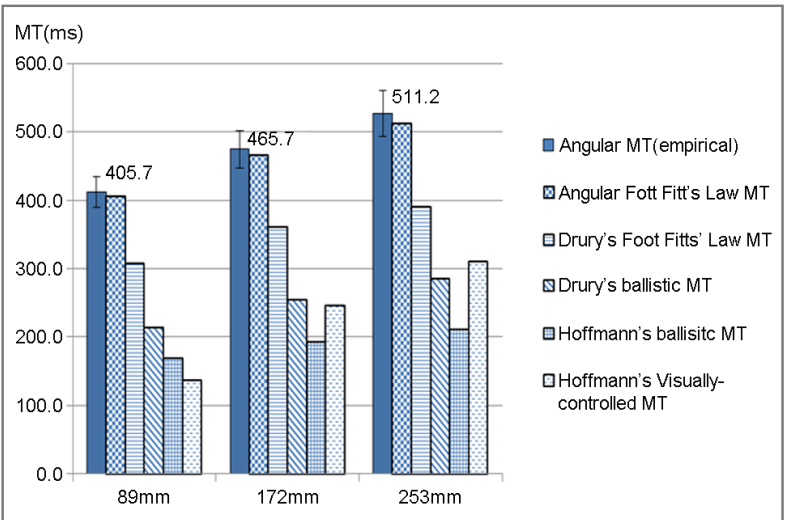

Figure 3. Aangular and linear MTs for linear distance

이 구간에 대해 기존의 모델들은 모두 벗어나 있다. 즉 기 존 모델들은 수평적인 움직임에 초점을 두고 개발되었으므 로 호를 그리는 움직임을 예측한 운동 시간은 모두 과소 평 가되어 있다.

앞선 결과에 대해 모델에 적용한 값은 직선 거리이므로 실 제 발의 이동 거리인 호의 길이보다 짧다. 따라서 기존 모델 값이 운동 시간을 예측하는 데 이러한 영향으로 과소 평가된 것인지 확인하기 위해 타겟 간의 호의 길이를 각 모델에 적 용해서 예측한 운동 시간을 비교하여 Figure 4 와 같은 기존 모델의 예측값을 얻었다.

호의 길이는 $89 \mathrm{~mm}$ 에서 $96.8 \mathrm{~mm}$ 로, $172 \mathrm{~mm}$ 에서 193.6 $\mathrm{mm}$ 로, $253 \mathrm{~mm}$ 에서 $290 \mathrm{~mm}$ 로 앞서 적용한 직선 거리보다 길어졌다. 따라서, 새롭게 구한 예측값이 다소 증가하였다.

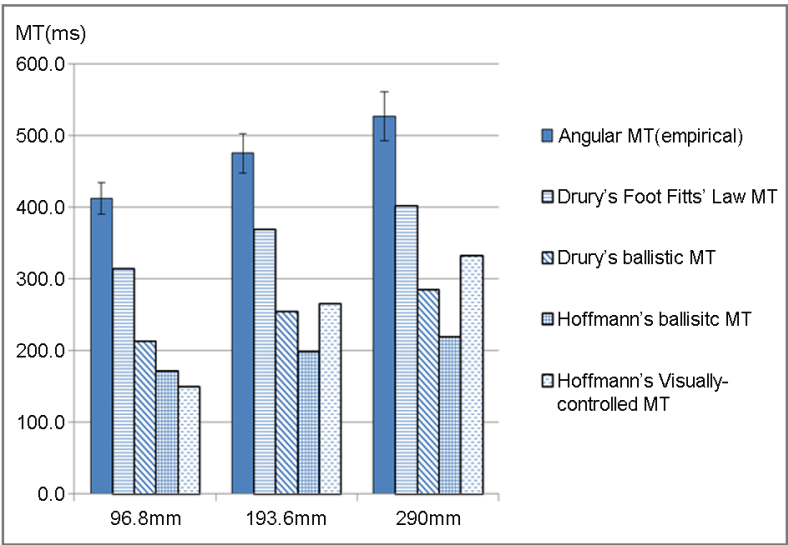

Figure 4. Angular and linear MTs for arc distance 
이를 앞서 구한 신뢰구간에 비교하면 거리가 길어졌음에도 불구하고 모델의 예측값은 여전히 호를 그리는 움직임을 과 소 평가하고 있음을 알 수 있다.

두 결과를 종합해 볼 때, 타겟 간의 운동 시간을 수평적인 움직임으로 예측하는 기존의 foot Fitts' law는 뒤꿈치가 고 정되어 축이 있는 각도의 움직임인 angular movement를 나타내는 데 과소 평가하고 있음을 알 수 있다.

\subsection{Development of angular foot Fitts' law}

실험 결과에서 확인한 바와 같이 기존의 linear foot Fitts' law는 angular movement를 설명하는 데 한계가 있다. 따 라서 호를 그리는 형태의 움직임을 표현하는 angular foot Fitts' law를 개발할 필요성이 있다.

모델을 개발하기 위해 Hoffmann(1988)이 언급한 바와 같이 페달 조작 시에 페달의 너비가 유의한 영향을 미치지 않는 ballistic movement Fitts' law를 참조하였다. 이는 페 달 간의 거리로 난이도(ID) 가 결정되며, 모델은 Equation 6 과 같다.

$$
\text { Angular MT }=251.9+16.3 \sqrt{A} ; r^{2}=0.99
$$

실험에서 사용된 페달 간의 거리가 MT에 유의한 영향을 미쳤으며 이 결과를 이용하여 Fitts' law equation을 도출하 였다. 모델 개발에는 실험에 참가한 피실험자 11 명 중 8 명의 데이터가 사용되었고, 나머지 3 명의 데이터는 모델 검증을 위해 남겨두었다. 모델은 OC (Operating Characteristics) curves에 의해 신뢰수준 $95 \%$ 에서 검정력 $80 \%$ 를 가지고 있다.

Equation 6에서 상수 251.9와 16.3은 선형회귀분석을 통 해 결정되었다. $\mathrm{A}$ 는 amplitude로서 페달 간의 거리를 나 타내며 단위는 mm이다. Equation 6의 값은 모든 angular movement가 나타나는 페달 조작 과제에 대해 확정된 값이 아니라 실험 데이터에 의존한다. 검증을 위해 모델 개발 과 정에서 제외된 데이터와 회귀분석 결과 $r^{2}=0.99$ 로 모델이 angular movement의 추세를 잘 설명하고 있음을 알 수 있다.

Angular foot Fitts' law로 예측한 값 $(89 \mathrm{~mm}-405.7 \mathrm{~ms}$, $172 \mathrm{~mm}-465.7 \mathrm{~ms}, 253 \mathrm{~mm}-511.2 \mathrm{~ms}$ ) 과 기존 foot Fitts' law model의 예측값을 비교하면 Figure 3과 같다. Angular foot Fitts' law의 예측값은 실험을 통해 얻은 각 수준의 $95 \%$ 신뢰구간 $89 \mathrm{~mm}(385.96<\mu<438.36), 172 \mathrm{~mm}$ (442.73< $\mu<507.17), 253 \mathrm{~mm}(486.78<\mu<566.33)$ 에 속 하여 모델 예측값이 통계적으로 유의함을 알 수 있다.

\section{Discussion}

기존 연구에서는 발 동작에 대한 운동 시간을 예측하기 위 해 페달 간의 거리를 중심으로 예측 시간을 구할 수 있는 모 델을 개발하였고(Drury, 1975) 시각적인 기능을 추가하였 다(Hoffmann, 1991b). 그러나 기존의 foot Fitts' law는 수 평적인 발 운동에 초점을 두고 있어 실제 페달 조작을 모두 설명하기에는 부족함이 있다. 특히 운전 중 페달 조작에 대 한 기존 연구를 살펴보면, John(2002)은 후방 충돌 회피 시 스템(the Rear End Collison Avoidance System: RECAS) 에 관한 연구에서 실제 운전자가 엑셀레이터에서 브레이크를 밟기까지 걸린 최단 시간을 측정하였다. 측정 결과, 개인차 를 고려하고도 400 500ms의 운동 시간이 소요됨을 밝혔다. 또한 Salvucci(2006)는 ACT-R (the Adaptive Control of Thought-Rational) 인지아키텍처를 이용한 인간의 운전 행 동을 묘사하는 모델에서 엑셀레이터와 브레이크 간의 발 운 동 시간을 $500 \mathrm{~ms}$ 로 적용하였다. 실험 결과를 통해서도 알 수 있듯이 호를 그리는 발 동작은 약 412 526ms의 운동 시간을 나타내고 있어 기존 연구 결과와 부합하는 운동 시 간을 나타내고 있다. 반면 기존 foot Fitts' law의 예측값은 130 390ms의 분포를 보이고 있어 실제 운동 시간에 못미 치고 있다. 각 수준에서 적게는 약 $100 \mathrm{~ms}$, 많게는 $300 \mathrm{~ms}$ 까지 차이가 난다. 또한 실험 데이터의 $95 \%$ 신뢰구간에 기 존 모델 예측값이 속하지 않음을 보였다. 이를 통해 실제 운 전 중 발 동작의 경우 기존 foot Fitts' law는 예측 시간을 과소 평가하고 있으며, 실제 운전 환경에서는 수평적인 발 운동보다는 호를 그리는 발 운동이 나타나고 있음을 알 수 있다.

기존의 foot Fitts' law가 호를 그리는 angular movement 의 movement time을 예측하지 못하는 가장 큰 이유는, 발 꿈치를 축으로 사용하는 운동 형태를 묘사하는 데 한계가 있기 때문이다. 반면 angular movement는 축을 사용하기 때문에 발 운동에 제약을 주게 되어 자유로운 움직임을 방해 하므로 운동 시간이 증가하게 되는 현상을 잘 설명한다. 운 전 중 이러한 운동 형태가 나타나는 이유는 다리의 무게로 인해 다리를 계속 들고 있을 수 없고 신체를 지탱하기 위해 축이 필요하기 때문이다.

본 연구 결과 운동 시간은 412 526ms로 나타났고 각 수준에서 기존 모델과 적게는 약 $100 \mathrm{~ms}$ 에서 많게는 $300 \mathrm{~ms}$ 정도 차이가 난다. 이는 매우 짧은 시간임에 분명하다. 그 러나 이것을 중요하지 않다고 할 수 없다. 예를 들어 시속 $100 \mathrm{~km}$ 로 주행하는 차량의 경우 0.5 초 사이에 $14 \mathrm{~m}$ 를 진행 한다. 즉 0.5 초만 잘못 행동하더라도 큰 사고로 이어질 수 있다. 특히 특수차량의 경우 더욱 위험하다. 또한 자동차가 
아니더라도 최근 다양한 인터페이스의 개발로 인해 발을 이 용한 컨트롤러가 많아졌다. 특히 치과 또는 외과를 포함한 병원 기관에서는 세균 감염 등의 이유로 청결에 각별히 유의 하고 있으므로 가급적 불필요한 행동에 손을 사용하지 않는 다. 때문에 진료나 수술 시에 환자의 높낮이를 조절하는 경 우 또는 수술 기구의 작동을 조절하는 등의 상황에서 발로 조작이 가능한 컨트롤러를 사용한다. 따라서 이러한 시스템 의 설계 및 개발 시에 기존의 foot Fitts' law만으로 사용자 의 행동을 모델링하는 것은 적합하지 않다. 호를 그리는 형 태의 움직임이 함께 고려되어야 한다.

따라서 angular foot movement와 같이 뒤꿈치가 고정 된 상태에서 움직임을 나타내는 angular foot Fitts' law인 Equation 6을 제안하였다. 이를 통해 페달 조작 방식에서 나타나는 호를 그리는 움직임의 운동 시간을 잘 예측할 수 있다. 이와 같이 발 동작 또한 수평적인 움직임과 함께 호를 그리는 형태로 다양하게 나타내는 것은 큰 의미가 있다.

본 연구는 호를 그리는 발 동작의 운동 시간을 비교해보고 자 이를 명확히 나타낼 수 있는 실험을 진행하였다. 그러나 실험 중 피실험자들은 추가적인 지시사항이나 다른 형태의 과제를 부여받지 않았다. 이는 Fitts' law가 나타내는 운동에 대해 기본 행태를 확인하기 위한 것으로 반복적인 과제를 가 능한 정확하고 빠르게 하도록 계획된 실험이다. 따라서 이를 확장하기 위해 향후 계산이나 의사결정과 같은 인지 과정이 포함된 추가적인 연구가 필요하다. 또한 타겟 너비와 타겟 간의 거리, 그리고 각도를 다양하게 구성해야 한다. 이와 함 께 발 뿐 아니라 손, 눈 등의 신체 다른 부분과 협응 작용을 통해 통합적인 인지 과정과 운동 행태를 나타낼 수 있는 연 구가 진행될 것으로 기대된다.

또한 Fitts' law 연구는 인간의 운동 시간을 예측하는 데 매우 유용하기 때문에 여러 시스템 인터페이스 조작을 표현 했다. 특히 손 동작에 관련된 연구가 많이 있었는데 그 중에 서도 2 차원 또는 3 차원으로 연구가 확장되고 발전되는 과정 에서 각도를 통해 움직임을 설명하는 많은 연구가 있었다 (Mackenzie and Buxton, 1992; Cha and Myung, 2010; Murata and Iwase, 2001). 특히 Cha and Myung (2010) 은 Fitts' law를 통해 손을 이용한 포인팅 과제에서 기존의 난이도(ID)에 경사각과 방위각을 추가하여 확장시키는 방법 으로 손의 3 차원 운동을 나타내었다. 따라서 이와 같은 접근 방식으로 발 운동에 대해서 추가적으로 각도 $(\theta)$ 를 반영할 수 있는 난이도(ID)를 확장하여 foot Fitts' law를 나타낼 수 있을 것으로 사료된다. 이를 통해 발 동작 또한 수평적인 움직임과 다른 호를 그리는 형태로 다양하게 나타낼 수 있고 각도를 이용하여 foot Fitts' law의 시야를 넓힐 수 있다.

발은 손에 비해 느리고 정확성이 떨어지는 단점이 있음에 도 불구하고 시스템을 조작하는데 보조적인 도구로서 매우
유용하게 사용되고 있다. 자동차는 물론 병원 등에서도 그 유용성을 입증하고 있으며, 손을 사용하지 못하는 장애인의 경우 한계를 극복하기 위해 발이 많이 사용된다. 이러한 이 유로 발을 이용할 수 있는 다양한 형태의 인터페이스가 개 발되고 있다. 특히 Kim and Kaber(2009)는 페달을 이용하 여 dynamic text-editing이 가능한 시스템을 제안하였다. 이를 통해 팔을 자유롭게 사용하지 못하는 경우 페달이 보조 입력도구로 유용함을 나타내었다. 또한 Chan et al.(2010) 은 발을 통해 터치 패드를 조작하는 입력 방식에 대해 사용 성 평가를 실시하였다. 이와 같이 발을 이용하는 여러 방식 의 인터페이스에서 발의 무게와 피로도로 인해 뒤꿈치를 축 으로 사용하는 angular movement가 나타나게 될 것이다. 이에 대한 사용성 평가와 장비를 개발함에 있어 발 운동을 잘 묘사할 수 있는 본 연구가 적용될 수 있을 것으로 기대 한다.

이와 함께 본 연구에서 제시하는 angular foot Fitts' law 는 model-based evaluation 기법에 적용할 수 있다. 실제 로 $\mathrm{GOMS}, \mathrm{ACT}-\mathrm{R}$ 과 같은 인지아키텍체에서는 인간 행동 을 나타내는 근거로 Fitts' law를 활용하고 있다. 특히 Park and Myung (2012)의 연구에서 ACT-R 인지아키텍처로 발 움직임을 묘사할 때 Fitts' law를 적용하여 사용성을 입증 하였다.

결론적으로 실제 움직임을 잘 나타내는 angular foot Fitts' law를 적용하여 호를 그리는 인간의 발 동작을 묘사하고 운 동 시간을 예측하는 것이 더 정확하며 사용자 인터페이스 평 가에 유용하게 적용될 수 있다.

\section{Conclusion}

본 연구를 통해 얻을 수 있는 결론은 다음과 같다.

첫째, 기존에 페달을 이용한 여러 연구를 바탕으로 이를 표현하는 모델들의 예측 시간과 실험 결과를 비교하여 운전 중 페달을 조작하는 실제 발 움직임은 호를 그리는 angular movement가 이루어지고 있음을 알 수 있다.

둘째, 실험 결과 기존의 수평적인 움직임에 초점을 두고 있는 foot Fitts' law는 angular movement가 나타나는 인 터페이스에서 운동 시간을 예측하는 데 한계가 있음을 알 수 있다. 또한 본 연구에서 제안한 angular foot Fitts' law 가 angular movement time을 잘 예측함을 알 수 있다.

셋째, 본 연구를 바탕으로 추후 Fitts' law에서 2차원 또 는 3 차원 운동과 같이 각도가 하나의 변수로 적용될 수 있 는 작업을 표현하는 연구에 적용할 수 있다.

넷째, 실제 움직임을 잘 나타내는 angular foot Fitts' law 
를 적용하여 인간의 발 동작을 묘사하고 운동 시간을 예측 하는 것이 더 정확하며 사용자 인터페이스 평가에 유용하게 적용될 수 있다.

\section{Acknowledgements}

This research was supported by Basic Science Research Program through the National Research Foundation of Korea (NRF) funded by the Ministry of Education, Science and Technology(2010-0013188).

\section{References}

Byrne, M. D. and Anderson, J. R., Perception and action, In Anderson, J. R. \& Lebiere, J., Eds. The Atomic Components of Thought, Mahwah, 167-200, NJ: Lawrence Erlbaum, 1998.

Campos, F. and Calado, J. M. F., Approaches to human arm movement control-A review, Annual Reviews in Control, 33(1), 69-77, 2009.

Cha, Y. and Myung, R., Extended Fitts' law in Three-Dimensional Pointing Tasks, Proceedings of the Human Factors and Ergonomics Society, 54, 972-976, 2010.

Chan, A. O. K., Chan, A. H. S., Ng, A. W. Y. and Luk, B. L., A Preliminary Analysis of Movement Times and Subjective Evaluations for a Visually-Controlled Foot-Tapping Task on Touch Pad Device, Proceedings of the International Multi Conference of Engineers and Computer Scientists, Vol. 3, 2010.

Davies, B. T. and Watts, J. M., Preliminary Investigation of Movement Time between Brake and Accelerator Pedals in Automobiles, Human Factors, 11, 407-410, 1969.

Drury, C. G., Application of Fitts' law to Foot-Pedal Design, Human Factors, 17, 368-373, 1975.

Fitts, P. M., The Information Capacity of the Human Motor System in Controlling the Amplitude of Movement, Journal of Experimental Psychology, 47, 381-391, 1954.

Fitts, P. M., Information Capacity of the Human Motor System in Controlling the Amplitude of Movement, Journal of Experimental Psychology, 67, 103-112, 1964.

Gan, K. C. and Hoffmann, E. R., Geometrical Conditions for Ballistic and Visually-Controlled Movements, Ergonomics, 31, 829-839, 1988.

Glaser, M. J. and Halcomb, C. G., Foot Placement and Respone Latency: A Test of Fitts' law, Proceedings of the Human Factors Society, 24th
Annual Meeting, 626-628, 1980.

Heimer, Lennart., The Human Brain and Spinal Cord: Functional Neuroanatomy and Dissection Guide, 2nd ed., Springer-Verlag Publishing, 1995.

Hoffmann, E. R., Accelerator to brake movement times, Ergonomics, 34, 3, 277-287, 1991a.

Hoffmann, E. R., A Comparison of Hand and Foot Movement Times, Ergonomics, 34, 397-406, 1991b.

John D. Lee., Collision Warning Timing, Driver Distraction, and Driver Response to Imminent Rear-End Collisions in a High-Fidelity Driving Simulator, Human Factors, 44, 2, 314-334, 2002.

Kim, J. Y. and Seo, K. B., The Effect of the Heel Rest on the Lower Leg Muscle Activity and Fatigue During Repetitive Pedaling, Journal of the Ergonomics Society of Korea, 24(4), 56-58, 2005.

Kim, J. S. and Jung, E. S., The Study Concerning Left Foot Inconvenience According to Relative Position of Clutch Pedal and Foot Rest, 2007 Fall Conference of Ergonomics Society of Korea, 370-371, 2007.

Kim, S. H., and Kaber, D. B., Design and Evaluation of Dynamic TextEditing Methods Using Foot Pedals, International Journal of Industrial Ergonomics, 39, 358-365, 2009.

Kroemer, K. H. E., Foot Operation of Controls. Ergonomics, 14, 333-361, 1971.

MacKenzie, I. S., A Note on the Information-Theoretic Basis for Fitts' law, Journal of Motor Behavior, 21, 323-330, 1989.

MacKenzie, I. S., Fitts' law as a Research and Design Tool in HumanComputer Interaction, Human-Computer Interaction, 7, 91-139, 1992.

MacKenzie, I. S. and Buxton., Extending Fitts' law to Two-Dimensional Tasks, ACM CHI, 219-226, 1992.

MacKenzie, I. S., Movement Time Prediction in Human-Computer Interface, Reading in HCI, 2, 483-493, 1995.

Miller, G. A., What is Information Measurement?, American Psychologist, 8, 3-11, 1953.

Morrison, R., Swope, J. and Halcomb, C., Movement time and brake pedal placement, Human Factors, 28, 2, 241-246, 1986.

Murata, A. and Iwase, H., Extending Fitts' law to a three-dimensional pointing task, Human Movement Science, 20(6), 791-805, 2001.

Park, B. H., Jung, H. S. and Lee, S. H. Analysis About How Human Foot Move During Driving Condition, Journal of the Korean Institute of Industrial Engineers, Vol, 38, No, 1, 41-45, 2012.

Park, J. and Myung, R., Enhancing Motor Module for Foot Movement in ACT-R Cognitive Architecture. Poster presented at the $10^{\text {th }}$ Asia Pacific Conference on Computer Human Interaction. 2012.

Salvucci D. D., Modeling Driver Behavior in a Cognitive Architecture, Human Factors, Vol, 48, No, 2, 362-380, 2006.

Welford, A. T., The Measurement if Sensory-Motor Performance: Survey and Reappraisal of Twelve Years's Progress, Ergonomics, 3, 189-230, 1960. 


\section{Author listings}

Jaeeun Park: smmio@korea.ac.kr

Highest degree: B.A, Management Information System, Yonsei University

Position title: MS candidate, Department of Industrial Management Engineering, Korea University

Areas of interest: HCI, Cognitive Modeling

\section{Rohae Myung: rmyung@korea.ac.kr}

Highest degree: Ph.D., Industrial Engineering, Texas Tech University Position title: Professor, Department of Industrial Management Engineering, Korea University

Areas of interest: HCI, Cognitive Modeling

Date Received : 2012-07-11

Date Revised :2012-09-24

Date Accepted : 2012-09-25 